\title{
Inhibition of ubiquitin protein expression and 20S proteasome activity by irbesartan prevents post-infarction ventricular remodeling and decreases $\mathrm{TNF}-\alpha$ generation
}

\author{
NAIJU ZHANG ${ }^{1 *}$, TIANPING CHEN ${ }^{2 *}$, CHUNFANG LIU $^{2 *}$, BI TANG $^{2}$, LING NIE $^{3}$, \\ HUILING AN ${ }^{3}$, DUILAN ZHAO ${ }^{3}$, LI PAN $^{3}$ and MEILING YU ${ }^{1}$
}

Departments of ${ }^{1}$ Pharmacy and ${ }^{2}$ Cardiovasology, The First Affiliated Hospital of Bengbu Medical College, Bengbu, Anhui 233004; ${ }^{3}$ Department of Pharmacy, Bengbu Second People's Hospital, Bengbu, Anhui 233000, P.R. China

Received July 24, 2013; Accepted August 30, 2013

DOI: 10.3892/br.2013.165

\begin{abstract}
Myocardial infarction (MI) may induce severe alterations of the cardiac contractile function that may, in turn, lead to heart failure (HF). The ubiquitin-proteasome system (UPS) plays a critical role in cardiac remodeling following MI. Angiotensin II type 1 receptor (AT1R) blockers effectively prevent left ventricular (LV) remodeling. However, it has not been elucidated whether the preventive effect of AT1R-blockers on LV remodeling is mediated through the UPS pathway. In the present study, with the use of cardiac morphometric parameters, haemodynamic measurements and enzyme-linked immunosorbent assay, we demonstrated that post-ischemic HF rats exhibited a significant increase in ventricular remodeling and irbesartan was effective in reversing cardiac remodeling. The expression of TNF- $\alpha$, ubiquitin protein and $20 \mathrm{~S}$ proteasome were significantly increased in the MI control group and irbesartan was shown to dose-dependently inhibit the expression of TNF- $\alpha$, ubiquitin protein and $20 \mathrm{~S}$ proteasome. In conclusion, it was hypothesized that UPS signaling is involved in ventricular remodeling following MI and the mechanism underlying the effect of irbesartan on ventricular remodeling may be associated with the downregulation of the expression of TNF- $\alpha$, ubiquitin protein and $20 \mathrm{~S}$ proteasome.
\end{abstract}

\section{Introduction}

Myocardial infarction (MI) may induce severe alterations of the cardiac contractile function that may, in turn, lead to heart failure (HF). Patients with HF exhibit progressive left

Correspondence to: Dr Meiling Yu, Department of Pharmacy, The First Affiliated Hospital of Bengbu Medical College, 287 Changhuai Road, Bengbu, Anhui 233004, P.R. China

E-mail: ziyuanznj@163.com

*Contributed equally

Key words: ventricular remodeling, irbesartan, heart failure, ubiquitine protein, $20 \mathrm{~S}$ proteasome ventricular (LV) dilation, ventricular remodeling and systolic dysfunction $(1,2)$. Ventricular remodeling, the main pathological process underlying chronic heart failure (CHF), is one of the determinants affecting morbidity and mortality. Therefore, the inhibition of ventricular remodeling is crucial in the prevention of HF. The ubiquitin-proteasome system (UPS) signaling pathway plays a critical role in the modulation of the development of cardiac remodeling. An increasing number of data indicate that the UPS is suppressed in CHF (3). The complexity of cardiac proteasomes provides dynamic regulatory venues for proteasome function (4). Detailed knowledge regarding proteasome dynamics in cardiac disease phenotypes is essential for the development of therapeutic strategies (4). Previous studies demonstrated an effective reduction of LV hypertrophy via the inhibition of proteasome function and proteasome inhibitors were used to prevent or even induce a regression of LV hypertrophy in animal models $(5,6)$.

The renin-angiotensin-aldosterone system is involved in the pathogenesis and progression of numerous cardiovascular and renal pathological conditions, including structural cardiac remodeling, MI, HF, hypertension and chronic kidney disease (7). Accumulating evidence indicates that angiotensin II is crucial in the transition from compensated to decompensated cardiac hypertrophy or failure $(8,9)$. Experimental studies also demonstrated that the inhibition of the renin-angiotensin system (RAS) with angiotensin II type 1 receptor (AT1R)-blockers improves cardiovascular function and remodeling and exerts beneficial effects on survival in post-ischemic HF rats $(10,11)$. Therefore, the aim of this study was to investigate whether the UPS signaling pathway is associated with the inhibition of cardiac remodeling induced by irbesartan.

\section{Materials and methods}

Animals. A total of 93 male Sprague-Dawley rats, weighing 200-250 g, were purchased from the Animal Center of Bengbu Medical College (Anhui, China). The rats were fed normal chow, had free access to water and were housed at a constant temperature of $21 \pm 1^{\circ} \mathrm{C}$ with a fixed 12-h light/dark cycle. The rats were anesthetized with an intraperitoneal injection of 3.5\% chloral hydrate sodium $(1 \mathrm{ml} / 100 \mathrm{~g})$ and were then intubated 
Table I. Haemodynamic parameters measured in anaesthetized rats in the different experimental groups.

\begin{tabular}{lcccrc}
\hline & \multicolumn{5}{c}{ Groups } \\
\cline { 2 - 6 } Parameters & Sham & MI-control & MI-Ir5 & Ml-Ir25 & Ml-Ir50 \\
\hline HR (bpm) & $400 \pm 15$ & $439 \pm 19^{\mathrm{a}}$ & $432 \pm 12$ & $424 \pm 25^{\mathrm{b}}$ & $413 \pm 22^{\mathrm{b}}$ \\
LVSP $(\mathrm{mmHg})$ & $90.21 \pm 1.40$ & $67.15 \pm 4.8^{\mathrm{a}}$ & $70.76 \pm 2.31$ & $75 \pm 1.83^{\mathrm{b}}$ & $85.13 \pm 0.85^{\mathrm{b}}$ \\
LVEDP $(\mathrm{mmHg})$ & $6.41 \pm 0.18$ & $27.23 \pm 0.43^{\mathrm{a}}$ & $25.09 \pm 1.06$ & $19.82 \pm 2.27^{\mathrm{b}}$ & $12.4 \pm 1.73^{\mathrm{b}}$ \\
$\mathrm{dP} / \mathrm{dt}_{\max }(\mathrm{mmHg} / \mathrm{s})$ & $3876.84 \pm 382.25$ & $1151.31 \pm 86.53^{\mathrm{a}}$ & $1297 \pm 46.80$ & $1876.55 \pm 2.83^{\mathrm{b}}$ & $2493.32 \pm 447.12^{\mathrm{b}}$ \\
$\mathrm{dP} / \mathrm{dt}_{\min }(\mathrm{mmHg} / \mathrm{s})$ & $3576.54 \pm 315.71$ & $934 \pm 265.68^{\mathrm{a}}$ & $987.98 \pm 8.81$ & $1257 \pm 9.37^{\mathrm{b}}$ & $1532 \pm 273.35^{\mathrm{b}}$ \\
\hline
\end{tabular}

$\mathrm{P}<0.05{ }^{\mathrm{a}}$ vs. sham and ${ }^{\mathrm{b}} \mathrm{vs}$. MI-control. Sham, sham-operated group ( $\left.\mathrm{n}=8\right)$; MI-control, untreated infarcted rats $(\mathrm{n}=12)$; MI-Ir5, -Ir25 and -Ir50, infarcted rats treated with irbesartan 5,25 and $50 \mathrm{mg} / \mathrm{kg} /$ day $(\mathrm{n}=10,10$ and 10 , respectively). Data are expressed as means \pm standard error of the mean. MI, myocardial infarction; HR, heart rate; LVSP, left ventricular systolic pressure; LVEDP, left ventricular end-diastolic pressure; $\mathrm{dP} / \mathrm{dt}_{\max }$, maximum rate of left ventricular pressure rise; $\mathrm{dP} / \mathrm{dt}_{\min }$, maximum rate of left ventricular pressure decrease; bpm, beats per minute.

and ventilated with a rodent respirator. A thoracotomy was performed at the fourth or fifth intercostal space in order to expose the heart. A 5-0 suture was placed under the left descending coronary artery and its circumflex branch and the suture ends were threaded through polyethylene tubes to form snares for reversible coronary artery occlusion. Perpetual ligation of the left anterior descending artery was performed and paleness of the anterior wall of the left ventricle indicated a successful model. The mortality rate within $24 \mathrm{~h}$ following this procedure was $\sim 46 \%$. Complete data regarding the infarct size were obtained from 46 rats (the rats that died and those with an infarct size occupying $<35$ or $>55 \%$ of the heart were excluded). The surviving rats were randomly divided into five groups: the placebo (control) group $(\mathrm{n}=12)$, the $\mathrm{Ir} 5$ group $(\mathrm{n}=10,5 \mathrm{mg} / \mathrm{kg} / \mathrm{day}$ irbesartan), the Ir25 group, ( $=10,25 \mathrm{mg} / \mathrm{kg} /$ day irbesartan), the Ir50 group ( $\mathrm{n}=10,50 \mathrm{mg} / \mathrm{kg} /$ day irbesartan) and the sham-operated group $(n=8)$. Except the sham-operated group, there was no difference in MI size and heart rate (HR) among the four remaining groups. Irbesartan was obtained from Hangzhou Sanofi Minsheng Pharmaceutical Co., Ltd. (Hangzhou, China). The sham-operated control animals underwent the same procedure, without coronary artery ligation. After the experiment, the rats were housed in polyethylene cages (3-4 rats/cage), fed standard laboratory chow and had free access to tap water, starting $24 \mathrm{~h}$ after the ligation and for a total of 6 weeks.

At the end of this study, $24 \mathrm{~h}$ after the last treatment, the rats were anesthetized with an intraperitoneal injection of $0.4 \mathrm{~g} / \mathrm{kg}$ chloral hydrate and deep anesthesia was maintained with intermittent intraperitoneal injections of $0.016 \mathrm{~g} / \mathrm{kg}$ chloral hydrate. A tracheotomy and endotracheal intubation were performed with a cannula connected to an animal respirator. The rats were ventilated with $\mathrm{O}_{2}$-enriched air at 70 breaths $/ \mathrm{min}$ and maintained the tidal volume at $1.0 \mathrm{ml} / 100 \mathrm{mg}$ body weight (BW). The body temperature was sustained at $37^{\circ} \mathrm{C}$ using a heating lamp. The haemodynamic parameters were measured continuously by intubation of the left common carotid artery, using the MedLab biological signal collecting and processing system (Nanjing Medease Science and Technology Co., Ltd., Nanjing, China). The standard electrocardiogram was also recorded continuously.

The hearts were arrested in diastole by intraperitoneal injection of $\sim 2-3 \mathrm{ml} \mathrm{KCl}$ and were removed from the animals, cleaned, dried on filter paper and weighed. Subsequently, the ventricles were separated and also weighed.

All the procedures were approved by the Ethics Committee for the use of experimental animals in Bengbu Medical College.

Determination of total cardiac collagen. Mallory's trichrome staining method was used to measure total collagen deposition in post-MI hearts with and without treatment. A total of 8 non-vascular areas were randomly selected in each slide under a microscope. The average was determined by a computer image analysis system.

TNF- $\alpha, 20 S$ proteasome and ubiquitin protein plasma concentrations. TNF- $\alpha, 20 \mathrm{~S}$ proteasome and ubiquitin protein detection was performed with the enzyme linked immunosorbent assay (ELISA) kit (Shanghai Yu Bo Biological Technology Co., Ltd., Shanghai, China), according to the manufacturer's instructions. The minimum level for detection was $2 \mathrm{ng} / \mathrm{l}$ and the concentration of TNF- $\alpha, 20 \mathrm{~S}$ proteasome and ubiquitin protein were calculated based on the standard curve.

Statistical analysis. Data are presented as means \pm standard error of the mean. The differences between the values obtained at 6 weeks were evaluated using analysis of variance (ANOVA), followed by Dunnett's or Kruskal-Wallis test. $\mathrm{P}<0.05$ was considered to indicate a statistically significant difference.

\section{Results}

Haemodynamic measurements. The haemodynamic parameters were measured in the anaesthetized animals 6 weeks following MI (Table I). Compared to the sham-operated group, the MI groups exhibited reduced values of left ventricular systolic pressure (LVSP), maximum rate of left ventricular pressure rise $\left(\mathrm{dP} / \mathrm{dt}_{\max }\right)$ and maximum rate of left ventricular pressure decrease $\left(\mathrm{dP} / \mathrm{dt}_{\min }\right)$, accompanied by increased values of HR and left ventricular end-diastolic pressure (LVEDP). The MI rats receiving irbesartan exhibited dose-dependently elevated values of LVSP, $\mathrm{dP} / \mathrm{dt}_{\max }$ and $\mathrm{dP} / \mathrm{dt}_{\min }$ compared to the control group. In addition, HR and LVEDP were dose-dependently decreased in the MI-Ir groups compared to the MI control group. 
Table II. Body weight and cardiac morphometric parameters measured in the different experimental groups.

\begin{tabular}{lccccc}
\hline & \multicolumn{5}{c}{ Groups } \\
\cline { 2 - 5 } Parameters & Sham & MI-control & MI-Ir5 & Ml-Ir25 & Ml-Ir50 \\
\hline BW (g) & $460 \pm 9$ & $459 \pm 8$ & $455 \pm 3$ & $441 \pm 7^{\mathrm{b}}$ & $424 \pm 6^{\mathrm{b}}$ \\
HW (g) & $1276 \pm 14$ & $1678 \pm 29^{\mathrm{a}}$ & $1629 \pm 46$ & $1466 \pm 31^{\mathrm{b}}$ & $1282 \pm 26^{\mathrm{b}}$ \\
HW/BW & $2.77 \pm 1.56$ & $3.69 \pm 3.63^{\mathrm{a}}$ & $3.60 \pm 15.3$ & $3.32 \pm 4.43^{\mathrm{b}}$ & $3.02 \pm 4.33^{\mathrm{b}}$ \\
CD of infact (\%) & & $62 \pm 6$ & $60 \pm 8$ & $55 \pm 7^{\mathrm{b}}$ & $50 \pm 4^{\mathrm{b}}$ \\
\hline
\end{tabular}

$\mathrm{P}<0.05{ }^{\mathrm{a}}$ vs. sham and ${ }^{\mathrm{b}} \mathrm{vs}$. MI-control. Sham, sham-operated group ( $\left.\mathrm{n}=8\right)$; MI-control, untreated infarcted rats $(\mathrm{n}=12)$; MI-Ir5, -Ir25 and -Ir50, infarcted rats treated with irbesartan 5,25 and $50 \mathrm{mg} / \mathrm{kg} / \mathrm{day}(\mathrm{n}=10,10$ and 10 , respectively). Data are expressed as means \pm standard error of the mean. MI, myocardial infarction; BW, body weight; HW, heart weight; CD, collagen density.

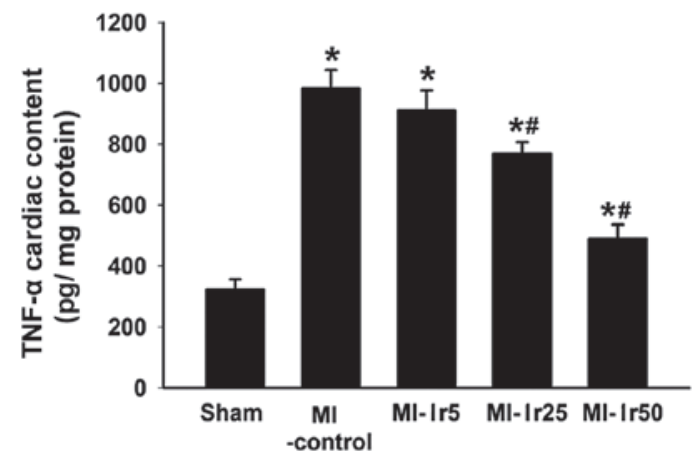

Figure 1. The effect of irbesartan on myocardial TNF- $\alpha$ content (pg of TNF- $\alpha$ per mg protein) from infarcted rat hearts was demonstrated by ELISA 6 weeks after myocardial infarction (MI). The results are expressed as means \pm standard error of the mean. $\mathrm{P}<0.05^{*}$ vs. sham and ${ }^{\#}$ vs. MI-control.

Cardiac morphometric parameters. Although BW did not differ between sham-operated and MI rats at the end of the treatment period, it was mildly reduced following treatment with irbesartan (Table II), despite similar food consumption among the five groups. Whereas in MI the heart weight (HW) and the HW/BW ratio were significantly increased, treatment with irbesartan significantly and dose-dependently reduced HW and HW/BW. Collagen density (CD) was found to be significantly increased in the infarcted myocardium and treatment with irbesartan dose-dependently reduced the collagen content.

Myocardial concentration of TNF- $\alpha$. A TNF- $\alpha$ concentration of $313 \pm 32 \mathrm{pg} / \mathrm{mg}$ was detected in the left ventricle of sham-operated rats (Fig. 1). This value was lower in the left ventricle of rats in the MI, MI-Ir5, -Ir25 and -Ir50 groups $(998 \pm 139 \mathrm{pg} / \mathrm{mg}$, $\mathrm{P}<0.01$ vs. sham; $911 \pm 56 \mathrm{pg} / \mathrm{mg}, \mathrm{P}<0.01$ vs. sham; $735 \pm 76 \mathrm{pg} /$ $\mathrm{mg}, \mathrm{P}<0.01$ vs. sham; and $501 \pm 69 \mathrm{pg} / \mathrm{mg}, \mathrm{P}<0.05$ vs. sham, respectively). Treatment with irbesartan ( 25 and $50 \mathrm{mg} / \mathrm{kg} / \mathrm{day})$ attenuated TNF- $\alpha$ concentration compared to the MI-control group $(\mathrm{P}<0.05)$. By contrast, no differences were observed between the MI-control and MI-Ir5 groups.

Ubiquitin protein concentration. Bar charts illustrating ubiquitin concentration in the sham, MI-control, MI-Ir5, MI-Ir25 and MI-Ir50 groups are presented in Fig. 2. In the sham group, the concentration of ubiquitin was significantly

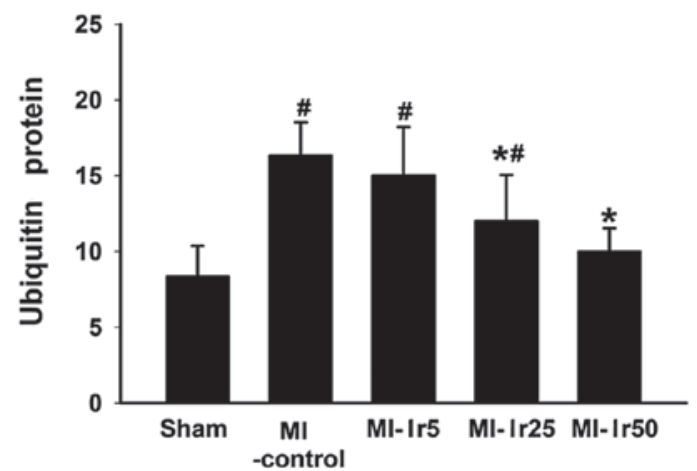

Figure 2. The effect of irbesartan on ubiquitin protein plasma concentration was demonstrated by ELISA 6 weeks after myocardial infarction (MI). The results are expressed as means \pm standard error of the mean. $\mathrm{P}<0.05^{\#} \mathrm{vs}$. sham and *vs. MI-control.

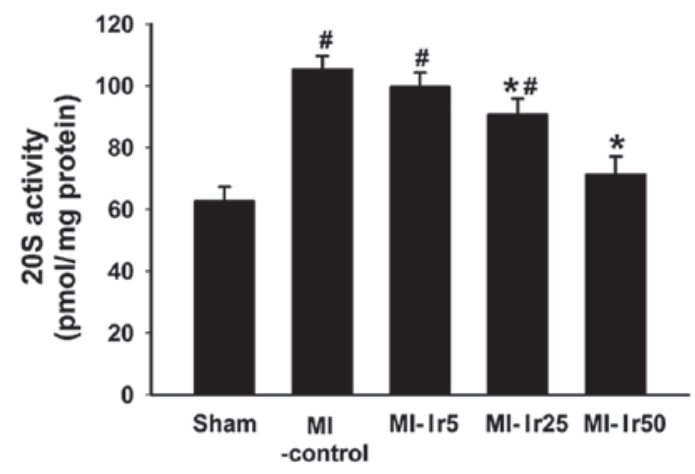

Figure 3. The effect of irbesartan on 20S proteasome plasma concentration was demonstrated by ELISA 6 weeks after myocardial infarction (MI). The results are expressed as means \pm standard error of the mean. $\mathrm{P}<0.05$. " Vs. sham and *v. MI-control.

lower compared to that in the MI-control, MI-Ir5 and MI-Ir25 groups $(\mathrm{P}<0.05)$. By contrast, no differences were observed between the MI-control and MI-Ir5 groups, or between the sham and MI-Ir50 groups.

$20 S$ proteasome activity. Bar charts illustrating 20S proteasome activity in the sham, MI-control, MI-Ir5, MI-Ir25 and MI-Ir50 groups are presented in Fig. 3. In the sham group, the $20 \mathrm{~S}$ proteasome activity was significantly lower compared to 
that in the MI-control, MI-Ir5 and MI-Ir25 groups $(\mathrm{P}<0.05)$. By contrast, no differences were observed between the MI-control and MI-Ir5 groups, or between the sham and MI-Ir50 groups.

\section{Discussion}

A major finding in the present study was the fact that the AT1R antagonist irbesartan strongly and dose-dependently improved the morphometric parameters and the haemodynamic status of the animals in the post-infarction rat model of CHF. Irbesartan was shown to prevent post-infarction ventricular remodeling through the inhibition of ubiquitin protein expression and $20 \mathrm{~S}$ proteasome activity and to decrease TNF- $\alpha$ generation.

MI Sprague-Dawley rats were orally treated with irbesartan for 6 weeks $(5,25$ or $50 \mathrm{mg} / \mathrm{kg} /$ day $)$. Subsequently, morphology and cardiac haemodynamics were assessed. From the morphological and cardiac haemodynamic point of view, the post-infarction CHF rat model was characterized by an important cardiac remodeling process including the HW/BW ratio and $\mathrm{CD}$. Compared to the sham-operated group, the HW/BW ratio, CD and LVEDP were significantly increased in the MI control group, whereas LVSP and LV contractility $(\mathrm{dP} / \mathrm{dt})$ were significantly reduced. These pathophysiological alterations in the cardiac structure and function were shown to be intimately associated with increased morbidity and mortality $(1,2)$.

An increased tissue RAS activity is likely to play a key role in the development of cardiac hypertrophy, remodeling and hypertension. The RAS components, including renin, constitute an autocrine/paracrine system in the myocardium (12). The inhibition of the renin-angiotensin-aldosterone system is therefore a therapeutic target. Angiotensin-converting enzyme inhibitors block the conversion of angiotensin I to angiotensin II and angiotensin receptor blockers selectively antagonize angiotensin II at the AT1Rs (13). Irbesartan, a specific AT1R-blocker, was shown to prolong survival in CHF rats (14) by improving LV function and haemodynamics. In addition, irbesartan was shown to interfere with the cardiac remodeling process by preventing hypertrophy and the development of pericoronary fibrosis (10). Our study demonstrated that irbesartan strongly and dose-dependently reduced the HW/BW ratio and CD and limited the elevation of LVEDP in MI rats. Furthermore, irbesartan increased dP/dt and cardiac index values. Therefore, treatment with the AT1R-blocker irbesartan attenuated the development of cardiac remodeling. Our observations were also consistent with the results of previous experimental studies, which suggested that AT1R-blockers attenuated myocardial remodeling in diabetic and post-infarcted hearts $(15,16)$ and demonstrated that irbesartan may significantly attenuate the structural and functional remodeling induced by experimental thyrotoxic cardiomyopathy (17).

A previous study demonstrated that TNF- $\alpha$ is elevated in patients with acute MI (18). Moreover, clinical and experimental data verified that the increased expression of TNF- $\alpha$ may expedite the progress of ventricular remodeling and further compromise cardiac function (19). However, rat cardiac function was shown to improve with TNF- $\alpha$ receptor knockout (20). Our study demonstrated that, compared to the sham-operated group, TNF- $\alpha$ was significantly increased in the
MI control group. It was previously reported that an increase in AT1R density was observed in the peri-infarction and infarction zones of the myocardium following MI in rats (21). It was also demonstrated that AT1R-blockers were able to reduce soluble TNF- $\alpha$ levels in patients with HF $(22,23)$. Our study demonstrated that irbesartan strongly and dose-dependently decreased TNF- $\alpha$ in MI rats.

Protein components of the UPS have also been identified in extracellular fluids, such as blood plasma and cerebrospinal, epididymal and bronchoalveolar fluids (24). To elucidate whether irbesartan reshapes the LV through the UPS signaling pathway, ubiquitin protein expression and 20S proteasome activity were assessed by ELISA. An increasing number of evidence indicates that patients with unstable angina pectoris (25) and those with CHF (26) exhibit different degrees of activation of the UPS. The present study demonstrated that ubiquitin and the $20 \mathrm{~S}$ proteasome were functionally active in post-infarction ventricular remodeling. These observations were also consistent with previous experimental results, which reported higher myocardial ubiquitin levels and proteasome activity in type 2 diabetic subjects with MI (27). We also observed that irbesartan mainly inhibited the activity of UPS, indicating that irbesartan may exert a therapeutic effect on post-infarction ventricular remodeling, partly via the inhibition of ubiquitin expression and 20S proteasome activity. This finding was consistent with those of previous studies, which demonstrated that the inhibition of the proteasome resulted in the prevention of or decrease in pressure-induced hypertrophy in animals $(6,28)$. UPS is an important quality control system for myocardial protein and an imbalance in this system may lead to HF (29). We concluded that an inappropriate increase in proteasome activity and the resulting acceleration of protein degradation may be the main mechanism underlying CHF. Therefore, the UPS pathway is crucial in post-infarction ventricular remodeling.

In conclusion, irbesartan delayed the exacerbation of post-infarction HF in rats through reversing cardiac remodeling. Cardiac UPS plays a critical role in the reversal of post-infarction HF by irbesartan in rats. Our study may provide novel insight into the mechanism underlying the beneficial effect of irbesartan on post-infarction HF. However, the upstream factors in the regulation pathway have yet to be determined. Therefore, the precise mechanism responsible for myocardial remodeling remains to be elucidated.

\section{Acknowledgements}

This study was supported by grants from the National Natural Science Foundation of China (81170046) and the Science Foundation of Bengbu City of China (no. 201103033).

\section{References}

1. Jessup M, Abraham WT, Casey DE, Feldman AM, Francis GS, Ganiats TG, Konstam MA, Mancini DM, Rahko PS, Silver MA, Stevenson LW and Yancy CW: 2009 focused update: ACCF/AHA guidelines for the diagnosis and management of heart failure in adults: a report of the American College of Cardiology Foundation/American Heart Association Task Force on Practice Guidelines: developed in collaboration with the International Society for Heart and Lung Transplantation. Circulation 119: 1977-2016, 2009. 
2. Dickstein K, Cohen-Solal A, Filippatos G, McMurray JJ, Ponikowski P, Poole-Wilson PA, Strömberg A, van Veldhuisen DJ, Atar D, Hoes AW, Keren A, Mebazaa A, Nieminen M, Priori SG and Swedberg K; ESC Committee for Practice Guidelines (CPG): ESC guidelines for the diagnosis and treatment of acute and chronic heart failure 2008: the Task Force for the Diagnosis and Treatment of Acute and Chronic Heart failure 2008 of the European Society of Cardiology. Developed in collaboration with the Heart Failure Association of the ESC (HFA) and endorsed by the European Society of Intensive Care Medicine (ESICM). Eur Heart J 29: 2388-2442, 2008.

3. Wohlschlaeger J, Sixt SU, Stoeppler T, Schmitz KJ, Levkau B, Tsagakis K, Vahlhaus C, Schmid C, Peters J, Schmid KW, Milting $\mathrm{H}$ and Baba HA: Ventricular unloading is associated with increased 20s proteasome protein expression in the myocardium. J Heart Lung Transplant 29: 125-132, 2010.

4. Drews O, Tsukamoto O, Liem D, Streicher J, Wang Y and Ping P: Differential regulation of proteasome function in isoproterenol-induced cardiac hypertrophy. Circ Res 107: 1094-1101, 2010.

5. Stansfield WE, Tang RH, Moss NC, Baldwin AS, Willis MS and Selzman CH: Proteasome inhibition promotes regression of left ventricular hypertrophy. Am J Physiol Heart Circ Physiol 294: H645-H650, 2008.

6. Hedhli N, Lizano P, Hong C, Fritzky LF, Dhar SK, Liu H, Tian Y, Gao S, Madura K, Vatner SF and Depre C: Proteasome inhibition decreases cardiac remodeling after initiation of pressure overload. Am J Physiol Heart Circ Physiol 295: H1385-H1393, 2008

7. Probstfield JL and O'Brien KD: Progression of cardiovascular damage: the role of renin-angiotensin system blockade. Am J Cardiol 105: 10A-20A, 2010.

8. Yamamoto E, Kataoka K, Shintaku H, Yamashita T, Tokutomi Y, Dong YF, Matsuba S, Ichijo H, Ogawa H and Kim-Mitsuyama S: Novel mechanism and role of angiotensin II induced vascular endothelial injury in hypertensive diastolic heart failure. Arterioscler Thromb Vasc Biol 27: 2569-2575, 2007.

9. Yamamoto E, Kataoka K, Yamashita T, Tokutomi Y, Dong YF, Matsuba S, Ogawa H and Kim-Mitsuyama S: Role of xanthine oxidoreductase in the reversal of diastolic heart failure by candesartan in the salt-sensitive hypertensive rat. Hypertension 50: 657-662, 2007

10. Gervais M, Fornes P, Richer C, Nisato D and Giudicelli JF: Effects of angiotensin II AT1-receptor blockade on coronary dynamics, function, and structure in postischemic heart failure in rats. J Cardiovasc Pharmacol 36: 329-337, 2000.

11. Richer C, Fornes P, Cazaubon C, Domergue V, Nisato D and Giudicelli JF: Effects of long-term angiotensin II AT1 receptor blockade on survival, hemodynamics and cardiac remodeling in chronic heart failure in rats. Cardiovasc Res 41: 100-108, 1999.

12. Whaley-Connell A, Habibi J, Cooper SA, Demarco VG, Hayden MR, Stump CS, Link D, Ferrario CM and Sowers JR: Effect of renin inhibition and AT1R blockade on myocardial remodeling in the transgenic Ren2 rat. Am J Physiol Endocrinol Metab 295: E103-E109, 2008.

13. Forni V, Wuerzner G, Pruijm M and Burnier M: Long-term use and tolerability of irbesartan for control of hypertension. Integr Blood Press Control 4: 17-26, 2011.

14. Richer C, Gervais M, Fornes P and Giudicelli JF: Combined selective angiotensin II AT1-receptor blockade and angiotensin I-converting enzyme inhibition on coronary flow reserve in postischemic heart failure in rats. J Cardiovasc Pharmacol 34 772-781, 1999 .
15. Tsutsui H, Matsushima S, Kinugawa S, Ide T, Inoue N, Ohta Y, Yokota T, Hamaguchi S and Sunagawa K: Angiotensin II type 1 receptor blocker attenuates myocardial remodeling and preserves diastolic function in diabetic heart. Hypertens Res 30: 439-449, 2007.

16. Zhang RY, Wang LF, Zhang L, Meng XN, Li SJ and Wang WR Effects of angiotensin converting enzyme inhibitor, angiotensin II type I receptor blocker and their combination on postinfarcted ventricular remodeling in rats. Chin Med J (Engl) 119: 649-655, 2006.

17. Kim BH, Cho KI, Kim SM, Kim JY, Choi BG, Kang JH, Jeon YK, Kim SS, Kim SJ, Kim YK and Kim IJ: Irbesartan prevents myocardial remodeling in experimental thyrotoxic cardiomyopathy. Endocr J 59: 919-929, 2012.

18. Biswas S, Ghoshal PK, Mandal SC and Mandal N: Relation of anti- to pro-inflammatory cytokine ratios with acute myocardial infarction. Korean J Intern Med 25: 44-50, 2010.

19. Bradham WS, Bozkurt B, Gunasinghe H, Mann D and Spinale FG: Tumor necrosis factor-alpha and myocardial remodeling in progression of heart failure: a current perspective. Cardiovasc Res 53: 822-830, 2002.

20. Kelly ML, Wang M,Crisostomo PR, Abarbanell AM, Herrmann JL, Weil BR and Meldrum DR: TNF receptor 2, not TNF receptor 1 , enhances mesenchymal stem cell-mediated cardiac protection following acute ischemia. Shock 33: 602-607, 2010.

21. Daniels MC, Keller RS and de Tombe PP: Losartan prevents contractile dysfunction in rat myocardium after left ventricular myocardial infarction. Am J Physiol Heart Circ Physiol 281: H2150-H2158, 2001.

22. Gurlek A, Kilickap M, Dincer I, Dandachi R, Tutkak H and Oral D: Effect of losartan on circulating TNFa levels and left ventricular systolic performance in patients with heart failure. J Cardiovasc Risk 8: 279-282, 2001.

23. Tsutamoto T, Wada A, Maeda K, Mabuchi N, Hayashi M, Tsutsui T, Ohnishi M, Sawaki M, Fujii M, Matsumoto T and Kinoshita M: Angiotensin II type 1 receptor antagonist decreases plasma levels of tumor necrosis factor alpha, interleukin-6 and soluble adhesion molecules in patients with chronic heart failure. J Am Coll Cardiol 35: 714-721, 2000.

24. Sixt SU and Dahlmann B: Extracellular, circulating proteasomes and ubiquitin - incidence and relevance. Biochim Biophys Acta 1782: 817-823, 2008.

25. Marfella R, Di Filippo C, Portoghese M, Siniscalchi M, Martis S, Ferraraccio F, Guastafierro S, Nicoletti G, Barbieri M, Coppola A, Rossi F, Paolisso G and D'Amico M: The ubiquitin-proteasome system contributes to the inflammatory injury in ischemic diabetic myocardium: the role of glycemic control. Cardiovasc Pathol 18: 332-345, 2009.

26. van Hees HW, Li YP, Ottenheijm CA, Jin B, Pigmans CJ, Linkels M, Dekhuijzen PN and Heunks LM: Proteasome inhibition improves diaphragm function in congestive heart failure rats. Am J Physiol Lung Cell Mol Physiol 294: L1260-L1268, 2008.

27. Barbieri M, Marfella R, Rizzo MR, Boccardi V, Siniscalchi M, Schiattarella C, Siciliano S, Lemme P and Paolisso G: The -8 UTR C/G polymorphism of PSMA6 gene is associated with susceptibility to myocardial infarction in type 2 diabetic patients. Atherosclerosis 201: 117-123, 2008.

28. Friehs I: Proteasome inhibition in hypertrophied myocardium. Am J Physiol Heart Circ Physiol 295: H1373-H1374, 2008.

29. Su H and Wang X: The ubiquitin-proteasome system in cardiac proteinopathy: a quality control perspective. Cardiovasc Res 85: 253-262, 2010 . 